\title{
Intensive support to improve clinical decision making in cardiovascular care: a randomised controlled trial in general practice
}

\author{
B D Friiling, C M Lobo, M E J L Hulscher, R P Akkermans, B B van Drenth, A Prins, \\ J C van der Wouden, R P T M Grol
}

See end of article for authors' affiliations

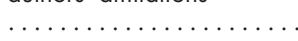

Correspondence to: Dr B D Frijling, Centre for Quality of Care Research University of Nijmegen, PO Box 9101, 6500 HB

Nijmegen, The

Netherlands;

frijling@knmg.nl

Accepted for publication 21 January 2003

\begin{abstract}
Objective: To evaluate the effects of feedback reports combined with outreach visits from trained nonphysicians on the clinical decision making of general practitioners (GPs) in cardiovascular care.

Design: Pragmatic cluster controlled trial with randomisation of practices to support (intervention group) or no special attention (control group); analysis after 2 years.

Setting: 124 general practices in The Netherlands.

Participants: 185 GPs.

Main outcome measures: Compliance rates for 12 evidence-based indicators for the management of patients with hypertension, hypercholesterolaemia, angina pectoris, or heart failure. The evaluation relied on the prospective recording of patient encounters by the participating GPs.

Results: The GPs reported 30101 clinical decisions at baseline and 22454 decisions after the intervention. A significant improvement was seen for five of the 12 indicators: assessment of risk factors in patients with hypercholesterolaemia (odds ratio $2.04 ; 95 \% \mathrm{Cl} 1.44$ to 2.88 ) or angina pectoris (3.07; 1.08 to 8.79$)$, provision of information and advice to patients with hypercholesterolaemia $(1.58,1.17$ to 2.13$)$ or hypertension $(1.55,1.35$ to 1.77$)$, and checking for clinical signs of deterioration in patients with heart failure $(4.11,2.17$ to 7.77$)$. Single handed practices, non-training practices, and practices with older GPs gained particular benefit from the intervention.

Conclusions: Intensive support from trained non-physicians can alter certain aspects of the clinical decision making of GPs in cardiovascular care. The effect is small and the strategy needs further development.
\end{abstract}

G eneral practitioners (GPs) are challenged to improve their clinical decision making for patients at high cardiovascular risk. High risk patients such as those with hypertension or cardiovascular disease should be given highest priority in preventive cardiology as they stand to gain the greatest benefits from medical treatment. ${ }^{1}$ The management of these patients in general practice is, however, not optimal. $^{2-4}$ The clinical decision making of GPs may be optimised by implementing evidence-based guidelines.

Specific strategies are needed to enhance implementation of clinical guidelines. ${ }^{5}$ Multifaceted interventions targeting different barriers to change tend to be more effective than single interventions. ${ }^{6}$ Educational outreach visits combined with social marketing appear to be a particularly promising approach to modifying health professional behaviour. ${ }^{7}$ In primary and secondary prevention of cardiovascular disease, multifaceted interventions delivered in outreach visits have been found to optimise practice organisation and the recording of risk factors. ${ }^{8-10}$ It remains, however, unclear whether intensive and multifaceted support is effective when targeted at GPs' decision making in daily cardiovascular care. It is possible that the complexity and multiplicity of clinical decision making provide barriers to successful implementation.

The aim of this study was to evaluate the effectiveness and costs of a multifaceted intervention targeted at various aspects of clinical decision making for patients at high cardiovascular risk in general practice. In order to tailor future interventions, we also explored a number of practice and patient characteristics to identify the predictors of success. The evaluation relied on the prospective recording of patient encounters by the participating practitioners. The study also therefore provided practical experience with applying such a measurement tool.

\section{BACKGROUND}

The present study is part of a series of studies which evaluated a randomised controlled trial on the quality of cardiovascular and diabetes care in general practice. ${ }^{11-18}$ A total of 124 practices with 185 GPs participated in this trial. Baseline assessments provided insights into the actual quality of care. ${ }^{11-14}$ The trial also showed the feasibility, effectiveness, and costs of a multifaceted intervention to improve certain elements of the structure, process, and outcome of care..$^{15-18}$ The intervention comprised feedback reports and outreach visits from trained non-physicians. The findings of the different studies are summarised in table 1 . The focus of the present study is thus on the effect of the intervention on various aspects of the process of care.

\section{METHODS}

The participants, intervention, assessments, randomisation, and statistical analysis have been described elsewhere ${ }^{17}$ and are reproduced here.

\section{Participants}

Practices in the southern part of The Netherlands were recruited via bulletins and by letter until a total of 124 practices were randomised. The recruitment lasted from May 1996 until May 1997. The inclusion criteria were the presence of a clinical computer system, employment of one or more practice assistants, and no major changes in personnel or premises planned during the course of the trial. We considered 
Table 1 Summary of a series of studies in a project on the quality of cardiovascular and diabetes care in general practice ( $n=124$ practices)

\begin{tabular}{|c|c|c|}
\hline Topic & Findings & Reference \\
\hline $\begin{array}{l}\text { Quality assessment } \\
\text { Practice organisation }\end{array}$ & $\begin{array}{l}\text { Teamwork in the practices has statistically significant relations with follow up and record keeping. A variety } \\
\text { of other practice organisational items appears not to be related to such activities. }\end{array}$ & 11 \\
\hline Clinical decision making & $\begin{array}{l}\text { GPs frequently provide information and advice in cardiovascular care. For several medical conditions, } 25 \% \\
\text { of the GPs perform less favourably. }\end{array}$ & 12 \\
\hline Clinical decision making & $\begin{array}{l}\text { GPs target at a diastolic blood pressure (DBP) of }<100 \mathrm{~mm} \mathrm{Hg} \text {, whereas guidelines recommend targeting } \\
\text { at a DBP of }<90 \mathrm{~mm} \mathrm{Hg} \text {. }\end{array}$ & 13 \\
\hline Risk perceptions & $\begin{array}{l}\text { Patients with hypertension or diabetes but no atherosclerotic disease have inadequate perceptions of their } \\
\text { absolute risk of cardiovascular events and thus need better risk information. }\end{array}$ & 14 \\
\hline \multicolumn{3}{|c|}{ Randomised controlled trial of multifaceted support from trained non-physicians } \\
\hline Practice organisation & $\begin{array}{l}\text { The intervention improves the organisation of cardiovascular and diabetes care. The duration of exposure } \\
\text { to certain aspects of organising such care is a key determinant to success. A variety of other characteristics } \\
\text { of the multifaceted support appear not to determine better practice organisation. }\end{array}$ & 15,16 \\
\hline Clinical decision making & $\begin{array}{l}\text { The intervention improves certain aspects of the clinical decision making of GPs in cardiovascular care. } \\
\text { The effect was, however, small and the strategy needs further development. }\end{array}$ & Present study \\
\hline Clinical decision making & $\begin{array}{l}\text { The intervention increases rates of foot examination and eye examination for patients with diabetes but } \\
\text { appears not to be effective in improving the pursuit of glycaemic control by GPs. }\end{array}$ & 17 \\
\hline Quality of life & $\begin{array}{l}\text { The intervention has a positive impact on several domains of the health related quality of life among } \\
\text { patients with diabetes or cardiovascular disease. }\end{array}$ & 18 \\
\hline
\end{tabular}

these criteria crucial for the conduct of the improvement project. Our offer included a certificate for six hours of accredited training for each participating GP (a GP in The Netherlands has to collect 40 hours of accredited training per year), and for the control group also feedback reports and 225 Euro per practice. The feedback reports for the control group were based on post-intervention measurement, supported by a manual to improve the general practice management of patients at high cardiovascular risk, and were sent after the trial. The first practices started their baseline measurement in November 1996 and the last practices finished their postintervention measurement in July 1999.

\section{Intervention}

The GPs in the intervention practices received feedback reports and support from facilitators to improve clinical decision making for patients with hypertension, hypercholesterolaemia, diabetes, angina pectoris, heart failure, transient ischaemic attacks, or peripheral arterial disease. The intervention comprised seven outreach visits per practice (one outreach visit per medical condition). Each practice received support from one facilitator; in partnerships, the facilitator could see more than one GP at the same time. Before each visit all GPs in the practice received a feedback report on the medical condition to be addressed during the visit. The feedback reports were based on baseline performance data and informed the GPs about their current clinical decision making in relation to the key recommendations from the national guidelines issued by the Dutch College of General Practitioners (DCGP). ${ }^{19-25}$ During the visit the facilitator and the GPs discussed the content of the feedback reports, prioritised specific aspects of decision making for improvement, and made change plans. The facilitator provided guidance, support, and educational materials to achieve improvement (box 1).

The intervention was part of a larger implementation project concerned with both practice organisation and clinical decision making with regard to patients at high cardiovascular risk. The focus of the project was on the implementation of a comprehensive programme of recommendations derived from the DCGP guidelines and consensus procedures. The facilitators conducted 15 outreach visits per practice, lasting an average of one hour per visit, equally distributed across a period of 21 months. The first eight visits concerned practice organis- ation; the other seven visits concerned clinical decision making. The protocol for the visits was highly standardised to limit variation and based on a model of change. ${ }^{8}$ The facilitators were specially trained to carry out the project protocol and to support the GPs. The training comprised lectures by the researchers ( 80 hours including 25 hours on clinical decision making for patients at high cardiovascular risk) and outreach visits in one pilot practice per facilitator. Each facilitator was supervised by one of the GP researchers during the entire

\section{Box 1 Support from the facilitators}

Each GP in the intervention group received support from a facilitator to improve the clinical decision making for patients at high cardiovascular risk. The support for each medical condition consisted of the following steps:

- Discussion of feedback reports based on national guidelines and baseline compliance rates. The facilitator asked about barriers to change and provided additional information in case the GP had doubts about specific results or recommendations.

- Selection of one or two of the following clinical issues for improvement: assessment of risk factors, provision of information and advice, prescription of medication, checking clinical parameters, and scheduling a follow up appointment. Criteria for selection were the preferences of the GP and his/her baseline levels of compliance.

- Selection of one or more of the following methods to achieve change: study of guidelines, specific articles, or other educational materials; knowledge tests; retrospective or prospective audit of personal clinical decision making; or arrangements for the practice organisation.

- Provision of materials and advice: during the visit the facilitator provided the GP with educational materials, knowledge tests, audit facilities, and advice for organisational arrangements, if necessary.

- Provision of a reminder: after the visit the facilitator made a written report of the plans and sent the report to the GP by mail.

- Evaluation: as part of a next visit the facilitator and the GP discussed the extent to which the plans were carried out, the impact of the change activities on the clinical decision making, and which aspects of clinical decision making needed further attention. 
Box 2 Example of outcome measures: the provision of information and advice to patients with treated hypertension

The hypertension guidelines issued by the Dutch College of General Practitioners in 1991 pertain to patients aged 18-80 years and define hypertension as a sustained diastolic blood pressure (DBP) of $95 \mathrm{~mm} \mathrm{Hg}$ or above. ${ }^{19}$ The target blood pressure in case of pharmacological treatment is a DBP of $\leqslant 90 \mathrm{~mm} \mathrm{Hg}$. The guidelines recommend GPs to provide treated hypertensive patients with advice on healthy lifestyle including smoking cessation, a body mass index (BMI) below $30 \mathrm{~kg} / \mathrm{m}^{2}$, and no excessive alcohol consumption. The guidelines also recommend nonpharmacological measures to control blood pressure including the reduction of salt consumption, body weight, and alcohol consumption. Furthermore, GPs should address a patient's compliance with treatment.

Using the guidelines, a panel of five GPs selected the following key recommendations with regard to the provision of information and advice at follow up visits of hypertensive patients aged $18-80$ years:

- discuss salt consumption in patients with uncontrolled hypertension*;

- discuss body weight in patients with uncontrolled hypertension* or BMl of $>30 \mathrm{~kg} / \mathrm{m}^{2}$;

- discuss alcohol consumption in patients with uncontrolled hypertension* or excessive alcohol consumption;

- advise current smokers to stop smoking;

- discuss compliance with treatment in patients on antihypertensive medication.

The recommendations are thus detailed descriptions of specific information or advice together with clinical situations calling for the provision of such information or advice.

The set of selected recommendations formed the indicator "treated hypertension, provision of information and advice". The compliance rate for the indicator was the number of clinical situations in which the GPs actually offered the recommended information or advice divided by the total number of clinical situations calling for such information or advice. The compliance rate for that indicator was one of the outcome measures of the present trial and the practice was the unit of analysis.

*Uncontrolled hypertension is DBP $>90 \mathrm{~mm} \mathrm{Hg}$ $195 \mathrm{~mm} \mathrm{Hg}$ or above for patients without antihypertensive medication).

intervention period. Most of the facilitators had worked as practice assistants in the past but none were trained physicians. In The Netherlands, practice assistants are qualified to perform administrative and organisational tasks (including the triage of patients) as well as medical activities such as blood pressure measurement and the provision of lifestyle advice.

\section{Outcome measures}

The outcome measures were the compliance rates for evidence-based indicators for the actual management of patients at high cardiovascular risk. We used the DCGP guidelines to identify the indicators. These guidelines are based on scientific evidence, broad consensus, and clinical experience. ${ }^{26}$ A group of five GPs, involved in research and guideline development but not participating in the trial, were asked to select the key recommendations from the guidelines. The recommendations are detailed descriptions of specific clinical actions together with the clinical situations calling for those actions. The selected key recommendations coincide with the recommendations from international guidelines. ${ }^{127-29}$ The key recommendations were grouped into indicators pertaining to specific aspects of cardiovascular care (see example in box 2). The outcome measures therefore indicated quality of clinical decision making and not just performance of clinical actions because the indicators also included the clinical situations calling for those actions.

After the trial we selected all the indicators which allowed detection of an absolute difference of $15 \%$ in the compliance rates between intervention and control groups with more than $90 \%$ power at a $5 \%$ level of significance. Changes in care provision are usually no more than $10 \% .^{30}$ None of the indicators concerning clinical decision making for transient ischaemic attacks or peripheral arterial disease met the selection criteria and the results for the indicators for diabetes are presented elsewhere. ${ }^{17}$ The 12 selected indicators are presented in table 3. The smallest difference we would have been able to detect across the indicators was $7 \%(\alpha=0.05, \beta=0.10)$. The post hoc power estimations take into account the design effect of cluster randomisation. ${ }^{31}$

\section{Assessments}

Using the key recommendations, forms were developed for the prospective recording of patient encounters for each of the medical conditions considered in the trial. Because of the high incidence of hypertension, separate forms were created for newly diagnosed and already treated (with or without medication) hypertension. The encounter forms included items pertaining to the age, sex, and clinical characteristics of the patient, and also the decisions regarding the performance (yes/no) of specific clinical actions. While the forms were based on the key recommendations, they did not contain any clues to the recommendations. GPs have been shown to complete similar forms reliably (kappa $=0.79$; Spies $\mathrm{TH}$, personal communication).

The GPs completed encounter forms during routine consultation hours at baseline and post-intervention measurement for a period of 2 months. They were asked to complete the forms immediately after eligible encounters. The data from the encounter forms were then entered into a computer by personnel blind to group allocation.

The characteristics of the participating practices were derived from a questionnaire completed by one GP per practice at baseline. Data were collected on type of practice (single handed versus partnership), practice location, number of GPs and practice assistants, working hours of each professional, age of GPs, patient list size, and involvement in GP vocational training.

\section{Costs}

The costs of the 21 month intervention were calculated using data provided by the facilitators and salary scales. The calculations included the time which the facilitators spent preparing and making the visits, their travel costs, and also the time spent by GPs to attend the visits. Moreover, the amount of time the GPs spent reading the feedback reports and carrying out the change plans was obtained by the facilitators and included in the calculations. The calculations did not include the costs for generating the feedback reports and training the facilitators because, per practice, these costs are strongly influenced by the number of participating practices.

The costs of the intervention for clinical decision making were estimated for the four medical conditions studied-that is, hypertension, hypercholesterolaemia, angina pectoris, and heart failure. An exact calculation was not possible because organisational arrangements and the implementation of guidelines for diabetes, transient ischaemic attacks, and peripheral arterial disease may also have influenced the clinical decision making studied. We estimated the costs of the intervention reported in this paper at $40 \%$ of the calculated costs for the entire 21 month intervention. 


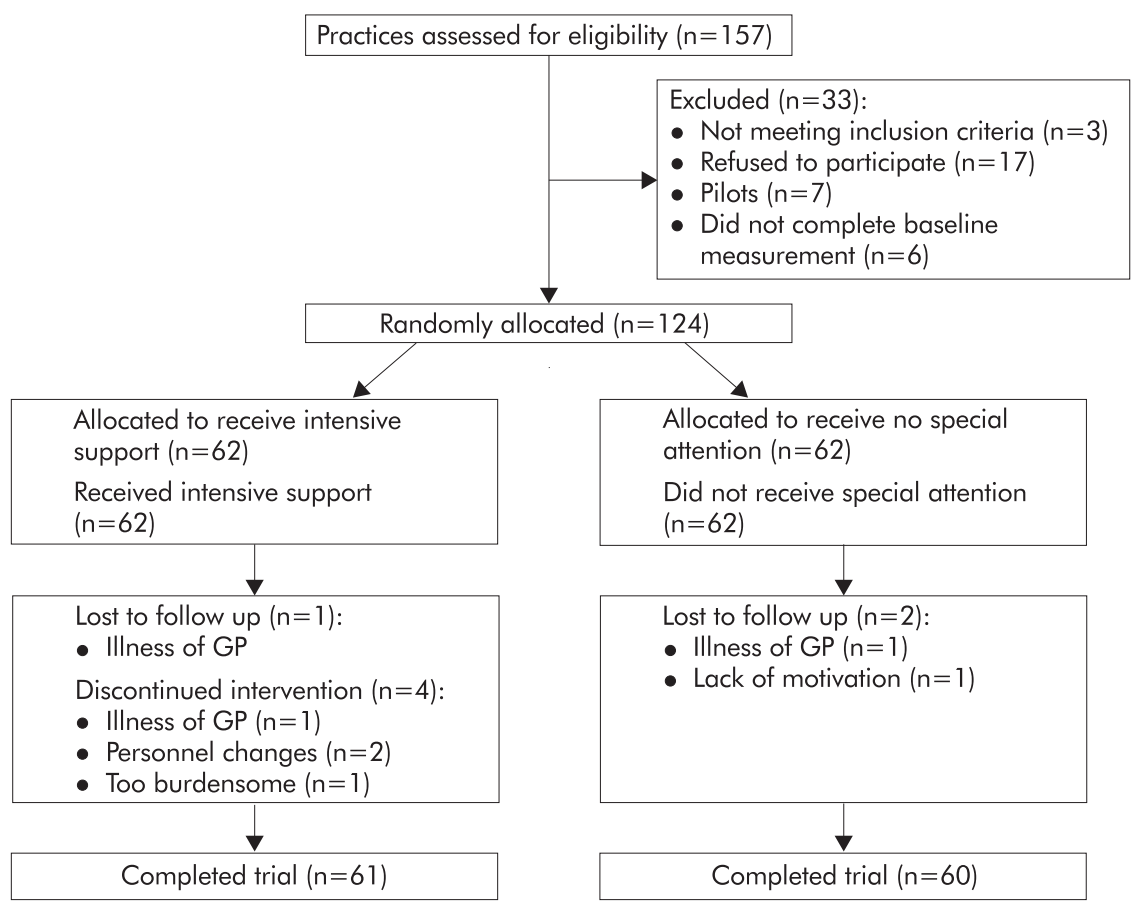

Figure 1 Profile of trial.

\section{Randomisation}

Immediately after the baseline measurement each practice was randomly allocated to receive intensive support (intervention group) or no special attention (control group). The practices were numbered and the person responsible for the randomisation process was blind to the practice identities. A random number generator was used to select permuted blocks with a block size of four. Practices were stratified according to practice type (single handed versus partnership) as this characteristic has been found to predict change in practice organisation. $^{8}$

Table 2 Practice characteristics at baseline and numbers of patient encounters

\begin{tabular}{|c|c|c|}
\hline & $\begin{array}{l}\text { Intervention } \\
\text { group }\end{array}$ & $\begin{array}{l}\text { Control } \\
\text { group }\end{array}$ \\
\hline \multicolumn{3}{|l|}{ Practices at baseline: } \\
\hline Total & 62 & 62 \\
\hline Single handed & $38(61 \%)$ & $38(61 \%)$ \\
\hline Mean age of GPs $>45$ years & $26(42 \%)$ & $24(39 \%)$ \\
\hline$<2500$ patients per full time equivalent GP & $22(35 \%)$ & $19(31 \%)$ \\
\hline Urban location* & $26(42 \%)$ & $25(40 \%)$ \\
\hline Training practice & $18(29 \%)$ & $17(27 \%)$ \\
\hline $\begin{array}{l}\geqslant 0.8 \text { full time equivalent practice } \\
\text { assistant employed per } 2500 \text { patients }\end{array}$ & $40(65 \%)$ & $44(71 \%)$ \\
\hline \multicolumn{3}{|l|}{ Patient encounters: } \\
\hline \multicolumn{3}{|l|}{ Newly diagnosed hypertension } \\
\hline Baseline & 122 & 153 \\
\hline Post-intervention & 93 & 107 \\
\hline \multicolumn{3}{|l|}{ Treated hypertension } \\
\hline Baseline & 1994 & 1854 \\
\hline Post-intervention & 1605 & 1725 \\
\hline \multicolumn{3}{|l|}{ Hypercholesterolaemia } \\
\hline Baseline & 247 & 288 \\
\hline Post-intervention & 174 & 172 \\
\hline \multicolumn{3}{|l|}{ Angina pectoris } \\
\hline Baseline & 169 & 166 \\
\hline Post-intervention & 148 & 97 \\
\hline \multicolumn{3}{|l|}{ Heart failure } \\
\hline Baseline & 121 & 115 \\
\hline Post-intervention & 75 & 76 \\
\hline
\end{tabular}

\section{Statistical analysis}

The practice was the unit of analysis for describing changes in clinical decision making. Data from the encounter forms were used to calculate the mean compliance rate for each indicator at baseline and the mean change from baseline. The compliance rate for an indicator was the number of decisions in accordance with the recommendation(s) of that indicator divided by the total number of decisions made with respect to that indicator. The calculations pertained mainly to clinical actions performed during the patient encounters included by the GPs. Particular actions were, however, also taken to be performed when the GP reported performance in a previous contact (such as advice on smoking cessation) or within the recommended period (such as blood pressure measurement within the last 12 months). Actions with missing data were considered not performed. As already mentioned, the calculations took detailed account of the clinical situations.

Multilevel logistic regression analysis (GLMMIX procedure in SAS) was used to assess the influence of the intervention on clinical decision making. ${ }^{31}$ Multilevel analysis takes into account the relatedness of the clinical decisions made within a particular practice. We also used these analyses to identify practice characteristics which were related to success of the intervention and to determine the influence of the baseline compliance rates of the different practices on the effect of the intervention. $p$ values of $<0.05$ were considered statistically significant.

\section{RESULTS}

A total of 157 practices were assessed for eligibility and 33 ( $21 \%$ ) were excluded (fig 1). Table 2 shows the baseline characteristics of the 124 participating practices (185 GPs) and the number of patient encounters. Four intervention practices $(4 / 62=6 \%)$ did not receive a per protocol intervention. These practices received feedback but no support from a facilitator with regard to clinical decision making. Three other practices were lost to follow up, so 121 practices (98\%) completed the trial (fig 1). In general, the age and sex of the patients were found to be evenly distributed between the intervention and control groups for the encounters at baseline and postintervention measurement. The proportion of men with 
Table 3 Baseline mean compliance rates and mean changes in compliance rates across practices by trial group

\begin{tabular}{|c|c|c|c|c|c|c|}
\hline \multirow{2}{*}{$\begin{array}{l}\text { Medical condition; indicator } \\
\text { (number of key recommendations } \\
\text { included in the indicator) }\end{array}$} & \multicolumn{2}{|c|}{ No of practices } & \multicolumn{2}{|c|}{ No of decisions } & \multicolumn{2}{|c|}{ Compliance rate (\%) } \\
\hline & Baseline & Post-intervention & Baseline & Post-intervention & $\begin{array}{l}\text { Baseline mean } \\
(95 \% \mathrm{Cl})\end{array}$ & $\begin{array}{l}\text { Mean change } \\
(95 \% \mathrm{Cl})\end{array}$ \\
\hline \multicolumn{7}{|c|}{ Newly diagnosed hypertension; assessment of risk factors (9) } \\
\hline Intervention & 46 & 40 & 1098 & 837 & 79 (75 to 83$)$ & $-2(-9$ to 5$)$ \\
\hline Control & 48 & 44 & 1377 & 963 & 75 (71 to 79$)$ & $0(-6$ to 6$)$ \\
\hline \multicolumn{7}{|c|}{ Newly diagnosed hypertension; provision of information and advice (10) } \\
\hline Intervention & 46 & 40 & 860 & 688 & $57(50$ to 65$)$ & $5(-6$ to 16$)$ \\
\hline Control & 48 & 44 & 1102 & 742 & $54(48$ to 60$)$ & $-1(-10$ to 8$)$ \\
\hline \multicolumn{7}{|c|}{ Treated hypertension; provision of information and advice (5) } \\
\hline Intervention & 62 & 61 & 4822 & 3585 & $64(59$ to 70$)$ & $5(-1$ to 10$)$ \\
\hline Control & 62 & 60 & 4567 & 3991 & 57 (52 to 63$)$ & $-3(-8$ to 2$)$ \\
\hline \multicolumn{7}{|c|}{ Treated hypertension; increasing the antihypertensive medication (1) } \\
\hline Intervention & 62 & 57 & 700 & 446 & 31 (26 to 37$)$ & $8(-1$ to 16$)$ \\
\hline Control & 61 & 60 & 681 & 567 & $32(28$ to 37$)$ & $4(-3$ to 11$)$ \\
\hline \multicolumn{7}{|c|}{ Treated hypertension; scheduling a follow up appointment (3) } \\
\hline Intervention & $62-r$ & 61 & 1756 & 1382 & 76 (72 to 80$)$ & $1(-4$ to 6$)$ \\
\hline Control & 62 & 60 & 1615 & 1551 & $72(66$ to 77$)$ & $0(-5$ to 5$)$ \\
\hline \multicolumn{7}{|c|}{ Hypercholesterolaemia; assessment of risk factors (9) } \\
\hline Intervention & 53 & 51 & 2223 & 1566 & 90 (87 to 93$)$ & $5(2$ to 8$)$ \\
\hline Control & 57 & 53 & 2592 & 1548 & 89 (86 to 92) & $2(-2$ to 5$)$ \\
\hline \multicolumn{7}{|c|}{ Hypercholesterolaemia; provision of information and advice (7) } \\
\hline Intervention & 53 & 51 & 1449 & 1036 & 77 (72 to 82$)$ & 7 (1 to 13$)$ \\
\hline Control & 57 & 53 & 1699 & 1019 & 77 (73 to 80$)$ & $0(-6$ to 6$)$ \\
\hline \multicolumn{7}{|c|}{ Angina pectoris; assessment of risk factors (2) } \\
\hline Intervention & 48 & 39 & 292 & 246 & 89 (85 to 93 ) & $8(2$ to 15$)$ \\
\hline Control & 46 & 24 & 280 & 170 & 92 (89 to 96$)$ & $0(-7$ to 6$)$ \\
\hline \multicolumn{7}{|c|}{ Angina pectoris; provision of information and advice (4) } \\
\hline Intervention & 48 & 39 & 341 & 348 & 69 (63 to 76$)$ & $-7(-18$ to 4$)$ \\
\hline Control & 46 & 24 & 325 & 222 & 67 (60 to 75$)$ & $-9(-23$ to 4$)$ \\
\hline \multicolumn{7}{|c|}{ Angina pectoris; prescribing aspirin and sublingual nitrate (2) } \\
\hline Intervention & 49 & 41 & 338 & 296 & 55 (48 to 62$)$ & $10(-1$ to 21$)$ \\
\hline Control & 49 & 26 & 332 & 194 & $54(48$ to 60$)$ & $1(-14$ to 17$)$ \\
\hline \multicolumn{7}{|c|}{ Heart failure; checking for clinical signs of deterioration (4) } \\
\hline Intervention & 41 & 25 & 460 & 300 & 78 (71 to 85$)$ & $12(0$ to 25$)$ \\
\hline Control & 36 & 22 & 484 & 304 & 83 (77 to 89$)$ & $-7 \quad(-17$ to 2$)$ \\
\hline \multicolumn{7}{|c|}{ Heart failure; provision of information and advice (3) } \\
\hline Intervention & 41 & 25 & 345 & 225 & 80 (73 to 86$)$ & $0(-8$ to 8$)$ \\
\hline Control & 36 & 22 & 363 & 228 & 79 (73 to 85$)$ & $6(-2$ to 15$)$ \\
\hline
\end{tabular}

*Increasing the dosage or starting a drug from a different class in case of a diastolic blood pressure above $90 \mathrm{~mm} \mathrm{Hg}$

treated hypertension at post-intervention, however, was lower for the intervention group than the control group $(39.2 \% \mathrm{v}$ $46.0 \%, p=0.003$, multilevel analysis). The GPs reported 30101 clinical decisions at baseline and 22454 decisions postintervention (table 3 ).

\section{Outcome measures}

The intervention resulted in statistically significant improvement for five of the 12 indicators (intention to treat analyses, table 4): assessment of risk factors in patients with hypercholesterolaemia or angina pectoris, provision of information and advice to patients with hypercholesterolaemia or treated hypertension, and checking for clinical signs of deterioration in patients with heart failure. Exclusion of those practices which did not provide data for a particular indicator either before or after the intervention had marginal effects on the findings for that indicator. Single handed practices, nontraining practices, and practices with older GPs benefited most from intensive support on the provision of information and advice to patients with hypercholesterolaemia or treated hypertension. Other practice characteristics were found to be associated with effects for only one or no indicators (table 5). The baseline compliance rates of the different practices did not influence the effect of the intervention.

Table 4 Effect size of the intervention on clinical decision making*

\begin{tabular}{|c|c|c|c|c|}
\hline Medical condition; indicator & Odds ratio & $95 \% \mathrm{Cl}$ & $p$ value & $\begin{array}{l}\text { Intracluster correlation } \\
\text { coefficient }\end{array}$ \\
\hline Newly diagnosed hypertension; assessment of risk factors & 1.07 & 0.77 to 1.47 & 0.696 & 0.08 \\
\hline Newly diagnosed hypertension; provision of information and advice & 1.32 & 0.94 to 1.86 & 0.109 & 0.17 \\
\hline Treated hypertension; provision of information and advice & 1.55 & 1.35 to 1.77 & $<0.001$ & 0.15 \\
\hline Treated hypertension; increasing the antihypertensive medication $\dagger$ & 0.87 & 0.61 to 1.24 & 0.432 & 0.06 \\
\hline Treated hypertension; scheduling a follow up appointment & 0.96 & 0.75 to 1.22 & 0.727 & 0.11 \\
\hline Hypercholesterolaemia; assessment of risk factors & 2.04 & 1.44 to 2.88 & $<0.001$ & 0.13 \\
\hline Hypercholesterolaemia; provision of information and advice & 1.58 & 1.17 to 2.13 & 0.003 & 0.09 \\
\hline Angina pectoris; assessment of risk factors & 3.07 & 1.08 to 8.79 & 0.037 & 0.00 \\
\hline Angina pectoris; provision of information and advice & 1.02 & 0.61 to 1.71 & 0.929 & 0.06 \\
\hline Angina pectoris; prescribing aspirin and sublingual nitrate & 1.44 & 0.86 to 2.41 & 0.168 & 0.03 \\
\hline Heart failure; checking for clinical signs of deterioration & 4.11 & 2.17 to 7.77 & $<0.001$ & 0.22 \\
\hline Heart failure; provision of information and advice & 0.85 & 0.43 to 1.67 & 0.636 & 0.13 \\
\hline
\end{tabular}

*Multilevel analysis with adjustments for baseline compliance, practice characteristics, and patients' age and sex.

†lncreasing the dosage or starting a drug from a different class in case of a diastolic blood pressure of $>90 \mathrm{~mm} \mathrm{Hg}$ 
Table 5 Practice characteristics predicting success $(p<0.05)$ of the intervention *

\begin{tabular}{|c|c|c|c|}
\hline Medical condition, indicator and practice characteristic & Odds ratiof & $95 \% \mathrm{Cl}$ & $\mathrm{p}$ value \\
\hline \multicolumn{4}{|l|}{ Treated hypertension; provision of information and advice } \\
\hline Non-training practice & 1.70 & 1.19 to 2.43 & 0.004 \\
\hline$<2500$ patients per full time equivalent GP & 1.52 & 1.11 to 2.08 & 0.008 \\
\hline$<0.8$ full time equivalent practice assistant employed per 2500 patients & 1.42 & 1.04 to 1.93 & 0.024 \\
\hline Single handed & 1.42 & 1.03 to 1.95 & 0.031 \\
\hline Mean age of GPs $>45$ years & 1.35 & 1.01 to 1.82 & 0.046 \\
\hline \multicolumn{4}{|l|}{ Hypercholesterolaemia; assessment of risk factors } \\
\hline$\geqslant 0.8$ full time equivalent practice assistant employed per 2500 patients & 3.11 & 1.38 to 6.98 & 0.006 \\
\hline \multicolumn{4}{|l|}{ Hypercholesterolaemia; provision of information and advice } \\
\hline Mean age of GPs $>45$ years & 4.21 & 2.19 to 8.09 & $<0.001$ \\
\hline Non-training practice & 2.87 & 1.28 to 6.44 & 0.011 \\
\hline Single handed & 2.66 & 1.29 to 5.49 & 0.008 \\
\hline
\end{tabular}

\section{Costs}

Our estimate of the average costs of the intervention for clinical decision making for the four medical conditions studied in this paper was 1500 Euros per practice. This included an average of 11 hours spent per GP in the intervention group.

\section{DISCUSSION}

Intensive support from facilitators improved the clinical decision making of GPs with regard to the assessment of risk factors and the provision of information and advice for certain types of patients at high cardiovascular risk, and also the checking for clinical signs of deterioration in patients with heart failure. Single handed practices, non-training practices, and practices with older GPs gained particular benefit from the intervention. The effects on the clinical decision making were, however, small and the average cost per practice was 1500 Euros.

The intervention may also ultimately improve patient outcomes. Identification of the presence of risk factors provides opportunities to reduce risk, whereas early detection of deterioration in patients with heart failure may promote adjustment of treatment and thereby prevent hospitalisation. ${ }^{32}$ Furthermore, the provision of information by doctors has been found to improve compliance with treatment, satisfaction with the care delivered, and health outcomes, whereas lifestyle interventions aimed at patients at high cardiovascular risk have been shown to reduce morbidity and mortality. ${ }^{33-36}$

Just why the intensive support was effective for five of the 12 indicators remains unclear. Comparison across the indicators is hindered by differences in the baseline compliance rates and power of the study. Moreover, we do not have insight into the motives of the GPs for apparently ignoring certain recommendations. All kinds of professional, patient, and environmental barriers may undermine clinical decision making. ${ }^{37}$ Remarkably, the trial did not show an increase in the prescription of recommended medication. This lack of an effect is in contrast to the findings of a review which showed that outreach visits reduced inappropriate prescribing. ${ }^{7}$

Our finding that single handed practices particularly benefited from the intensive support also contrasts with a previous study by Hulscher et $a l^{8}$ which found a positive relation between partnership and improving the organisation of cardiovascular disease prevention. One possible explanation for this discrepancy is that partnerships have more people available to optimise practice organisation while GPs in single handed practices do not have to share support for clinical decision making with other GPs. Partnerships, training practices, and practices with younger GPs seem to need extra support with the provision of information and advice.

Prospective recording of patient encounters proved feasible but had some drawbacks. For some indicators, such as the prescription of angiotensin converting enzyme inhibitors and other medication to patients with heart failure, an insufficient number of decisions were available to evaluate the effectiveness of the intervention adequately. The schedule of the trial did not allow us to lengthen the recording period. In addition, the GPs generally reported $18 \%$ fewer encounters at postintervention than at baseline, possibly due to a lack of motivation. Finally, prospective recording appears to be less suitable for the assessment of compliance with recommendations for the diagnosis of diseases and risk factors, because practitioners will obviously fail to include encounters in which they overlook the diagnosis.

\section{Limitations}

At the post-intervention measurement the GPs in the intervention group may have selectively recorded patient encounters in comparison with the control group, because the GPs were not blind to the allocation of their practice. Selective recording is nevertheless unlikely because the groups did not differ substantially in the number of patient encounters, mean age of patients, or the proportion of men. Moreover, the intervention did not improve compliance for all indicators.

Our study has several other limitations. The practices volunteered to participate and may therefore have been more interested and motivated than other practices. Furthermore, there were $25 \%$ fewer clinical decisions at post-intervention than at baseline. Bias due to the lower response at post-intervention is nevertheless unlikely because we took detailed account of the clinical situations when we assessed the compliance rates. Finally, we did not explore the effects on patient outcome. The outcome measures were nevertheless based on well accepted recommendations.

\section{Implications for the future}

Intensive support from non-physicians improved the clinical decision making for some aspects of cardiovascular care, but overall the effects were small. Research is needed to identify the barriers to change because insight into the factors which appear to prevent change will certainly help us to improve the present implementation strategy. The facilitators asked the GPs about barriers to change but may need more insight and training to be able to recognise and tackle these barriers. The effectiveness of support from non-physicians is important in terms of the costs compared with support from physicians. Furthermore, some effects of the intervention were more pronounced for certain practice characteristics. These findings suggest differences in the intensity of support required across practices and call for further research to explore the associations between practice and successful change. In our opinion, the strategy of having a non-physician to help GPs improve their clinical decision making merits further development. 


\section{Key messages}

- Many aspects of cardiovascular care in general practice need improvement

- A combination of feedback reports and outreach visits from trained non-physicians improved certain aspects of the clinical decision making of general practitioners in cardiovascular care.

- The effects on clinical decision making were small and the strategy needs further development.

\section{Authors' affiliations}

B D Frijling, M E J L Hulscher, R P Akkermans, B B van Drenth, R P T M Grol, Centre for Quality of Care Research, University of Nijmegen, P O Box 9101, 6500 HB Nijmegen, The Netherlands C M Lobo, A Prins, J C van der Wouden, Department of General Practice, Erasmus University Rotterdam, PO Box 1738, 3000 DR Rotterdam, The Netherlands

\section{REFERENCES}

1 Wood D, De Backer G, Faergeman O, et al. Prevention of coronary heart disease in clinical practice. Summary of recommendations of the Second Joint Task Force of European and other Societies on Coronary Prevention. J Hypertens 1998;16:1407-14.

2 Frijling BD, Spies TH, Lobo CM, et al. Blood pressure control in treated hypertensive patients: clinical performance of general practitioners. $\mathrm{Br} J$ Gen Pract 2001;51:9-14

3 Brady AJB, Oliver MA, Pittard JB. Secondary prevention in 24431 patients with coronary heart disease: survey in primary care. $B M$ 2001;322:1463.

4 Mair FS, Crowley TS, Bundred PE. Prevalence, aetiology and management of heart failure in general practice. Br J Gen Pract 1996:46:77-9.

5 Bero LA, Grilli R, Grimshaw JM, et al. Closing the gap between research and practice: an overview of systematic reviews of interventions to promote the implementation of research findings. BMU 1998;317:465-8.

6 Wensing M, van der Weijden T, Grol R. Implementing guidelines and innovations in general practice: which interventions are effective. $\mathrm{Br} J$ Gen Pract 1998:8:991-7.

7 Thomson O'Brien MA, Oxman AD, Davis DA, et al. Educational outreach visits: effects on professional practice and health care outcomes (Cochrane Review). In: The Cochrane Library, Issue 1. Oxford: Update Software, 2001.

8 Hulscher MEJL, van Drenth BB, van der Wouden JC, et al. Changing preventive practice: a controlled trial on the effects of outreach visits to organise prevention of cardiovascular disease. Qual Health Care 1997:6: 19-24

9 van Drenth BB, Hulscher MEJL, Mokkink HGA, et al. Effects of outreach visits by trained nurses on cardiovascular risk-factor recording in general practice. Eur J Gen Pract 1997;3:90-5

10 Moher M, Yudkin P, Wright L, et al. Cluster randomised controlled trial to compare three methods of promoting secondary prevention of coronary heart disease in primary care. BN 2001;322:1338-42.

11 Lobo CM, Frijling BD, Hulscher MEJL, et al. Organizational determinants of cardiovascular prevention in general practice. Scand J Prim Health Care 2003 (in press)

12 Frijling BD, Lobo CM, Hulscher MEJL, et al. Provision of information and advice in cardiovascular care: clinical performance of general practitioners. Patient Educ Counsel 2002;48:131-7.

13 Frijling BD, Spies TH, Lobo CM, et al. Blood pressure control in treated hypertensive patients: clinical performance of general practitioners. $\mathrm{Br} J$ Gen Pract 2001;51:9-14
14 Frijling BD, Lobo CM, Keus IM, et al. Perceptions of cardiovascular risk among patients with hypertension or diabetes. Patient Educ Counsel 2003 (in press)

15 Lobo CM, Frijling BD, Hulscher MEJL, et al. Improving quality of organizing cardiovascular preventive care in general practice by outreach visitors: a randomized controlled trial. Prev Med 2002;35:422-9.

16 Lobo CM, Frijling BD, Hulscher MEJL, et al. Organizing cardiovascular preventive care in general practice: determinants of a successful intervention. Prev Med 2002;35:430-6.

17 Frijling BD, Lobo CM, Hulscher MEJL, et al. Multifaceted support to improve clinical decision making in diabetes care: a randomized controlled trial in general practice. Diabetes Med 2002;19:836-42.

18 Lobo CM, Frijling BD, Hulscher MEJL, et al. Effect of a comprehensive intervention program on quality of life in patients at high cardiovascular risk: a randomised controlled trial. Qual Life Res 2003 (in press).

19 van Binsbergen JJ, Grundmeyer HGJM, van den Hoogen JPH, et al. NHG-Standaard Hypertensie (Dutch College of General Practitioners' guidelines on hypertension). Huisarts Wet 1991;34:389-95.

20 van Binsbergen JJ, Brouwer A, van Drenth BB, et al. NHG-Standaard Cholesterol (Dutch College of General Practitioners' guidelines on cholesterol). Huisarts Wet 1991;34:551-7.

21 van Binsbergen JJ, Gelpke JEH, van Bentum STB, et al. NHG-Standaard TIA (Dutch College of General Practitioners' guidelines on Transient Ischaemic Attack). Huisarts Wet 1995;38:15-25.

22 Bonsema K, Boutens EJ, Kaiser V, et al. NHG-Standaard Perifeer Arterieel Vaatlijden (Dutch College of General Practitioners' guidelines on peripheral arterial disease). Huisarts Wet 1990;33:440-6.

23 Cromme PVM, Mulder JD, Rutten GEHM, et al. NHG-Standaard Diabetes Mellitus Type II (Dutch College of General Practitioners' guidelines on Type 2 diabetes mellitus). Huisarts Wet 1989;32:15-18.

24 Rutten FH, Bohnen AM, Hufman P, et al. NHG-Standaard Angina Pectoris (Dutch College of General Practitioners' guidelines on angina pectoris). Huisarts Wet 1994;37:398-406.

25 Walma EP, Bakx HCA, Besselink RAM, et al. NHG-Standaard Hartfalen (Dutch College of General Practitioners' guidelines on heart failure). Huisarts Wet 1995;38:471-87.

26 Grol R, Thomas S, Roberts R. Development and implementation of guidelines for family practice: lessons from the Netherlands. Fam Pract 1995;40:435-9.

27 Guidelines Subcommittee of the WHO-ISH Mild Hypertension Liaison Committee. 1999 World Health Organization-International Society of Hypertension Guidelines for the Management of Hypertension. J Hypertens 1999:17:151-83.

28 Task Force on Stable Angina of the European Society of Cardiology. Guidelines for the management of stable angina pectoris Eur Heart J 1997; 18:394-413

29 Task Force on Heart Failure of the European Society of Cardiology Guidelines for the treatment of heart failure. Eur Heart $J$ 1997:18:736-53.

30 Grol R. Between evidence-based practice and total quality management: the implementation of cost-effective care. Int I Qual Health Care 2000:12:297-304.

31 Campbell MK, Mollison J, Steen N, et al. Analysis of cluster randomized trials in primary care: a practical approach. Fam Pract 2000;17:192-6.

32 Shah NB, Der E, Ruggerio C, et al. Prevention of hospitalizations for heart failure with an interactive home monitoring program. Am Heart J 1998; 135:373-8.

33 Roter DB, Hall JA, Merisca R, et al. Effectiveness of interventions to improve patient compliance: a meta-analysis. Med Care 1998;36:1138-61

34 Williams S, Weinman J, Dale J. Doctor-patient communication and patient satisfaction: a review. Fam Pract 1998;15:480-92.

35 Kaplan SH, Greenfield S, Ware JE. Assessing the effects of physician-patient interactions on the outcomes of chronic disease. Med Care 1989;27:S1 10-27.

36 Ketola E, Sipilä R, Mäkelä M. Effectiveness of individual lifestyle interventions in reducing cardiovascular disease and risk factors. Ann Med 2000:32:239-51.

37 Cabana MD, Rand CS, Powe NR, et al. Why don't physicians follow clinical practice guidelines? A framework for improvement. JAMA 1999;282: 1458-65. 